\title{
A conformação social do lixo e das tecnologias de triagem: o caso da transferência de Centrais Mecanizadas de Triagem em São Paulo
}

The social shaping of waste and sorting technologies: the case of MRFs transfer in São Paulo

Marcelo Alves de Souza[a] [D, Francisco de Paula Antunes Lima[b] (D), Cinthia Versiani Scott Varella[a] (D)

[a] Universidade Federal de Minas Gerais (UFMG), Belo Horizonte, MG, Brasil

[b] Universidade Federal de Minas Gerais (UFMG), Departamento de Engenharia de Produção, Belo Horizonte, MG, Brasil

Como citar: Souza, M. A., Lima, F. P. A., \& Varella, C. V. S. (2021). A conformação social do lixo e das tecnologias de triagem: o caso da transferência de Centrais Mecanizadas de Triagem em São Paulo. urbe. Revista Brasileira de Gestão Urbana, 13, e20200073. https://doi.org/10.1590/2175-3369.012.e20200073

\section{Resumo}

O que fazer com o lixo produzido em grande escala quando enterrar ou incinerar não são mais técnica, social e ambientalmente tolerados? Este artigo apresenta o caso do município de São Paulo, que optou pela transferência de Centrais Mecanizadas de Triagem europeias para ampliar sua capacidade de triagem de resíduos recicláveis e, assim, tentar responder parcialmente a essa questão. A partir do quadro metodológico utilizado, análise antropotecnológica e a Análise Ergonômica do Trabalho, foi possível revelar problemas decorrentes dessa transferência de tecnologia relacionados ao ambiente externo, ao processo produtivo interno e aos resultados. Os problemas evidenciados são retomados à luz do conceito de "antropotecnologia" de Alain Wisner, que pretende apoiar os projetistas na elaboração de projetos mais aderentes às realidades das situações encontradas nos países de destino. Ao final, sugestões de reprojeto desses sistemas são apresentadas, de modo a reduzir as pretensões da mecanização e automação na substituição do trabalho humano, propondo sistemas integrados homensmáquinas que resultem em melhor desempenho global.

Palavras-chave: Central mecanizada de triagem. Reciclagem. Transferência de tecnologia. Reprojeto. Catadores.

\begin{abstract}
What to do with waste produced on a large scale when burying or incinerating is no longer technically, socially and environmentally tolerated? This work presents the case of the municipality of São Paulo, which opted for the transfer of European materials recovery facilities (MRFs) in order to expand its capacity for sorting recyclable waste and, thus, trying to partially answer this question. From the methodological framework used, anthropotechnological analysis and the ergonomic analysis of work, it was possible to reveal problems arising from this technology transfer, related to the external environment, the internal production process and the results. The problems highlighted are taken up in the light of the concept of
\end{abstract}

MAS é engenheiro de Produção, doutorando e mestre em Engenharia de Produção, e-mail: marceloas86@gmail.com

FPAL é engenheiro Mecânico, pós-doutor em Ergologia, doutor em Ergonomia e mestre em Engenharia, e-mail: fpalima@ufmg.br

CVSV é engenheira de Produção, doutoranda e mestre em Engenharia de Produção, e-mail: cinthiaversiani@gmail.com 
"anthropotechnology" by Alain Wisner, which aims to support designers in the elaboration of projects more adherent to the realities of the situations found in the destination countries. In the end, suggestions for redesigning these systems are presented, in order to reduce the pretensions of mechanization and automation in the substitution of human labor, proposing integrated human-machine systems that result in better overall performance and production quality.

Keywords: Material recovery facility. Recycling. Technology transfer. Redesign. Waste pickers.

\section{Introdução}

O que fazer com o lixo urbano quando enterrar ou incinerar não são mais técnica, social e ambientalmente tolerados? A reciclagem, base da economia circular, é uma alternativa ainda incipiente, requerendo investimentos elevados e um tempo longo de implementação. A cidade de São Paulo, por exemplo, coletou 12.322 toneladas/dia de resíduos domiciliares no ano de $2012^{1}$, das quais apenas 197 toneladas/dia (1,6\%) foram coletadas seletivamente pelo sistema oficial do município (São Paulo, 2014). Essa situação tem levado gestores públicos de grandes metrópoles a buscar soluções em larga escala, dentre elas a mecanização da coleta e da triagem. 0 município de São Paulo, por exemplo, optou, em 2014, pela implantação de grandes plantas de triagem mecanizada, cada uma com capacidade nominal de 250 toneladas/dia. Porém, dados mais atualizados mostram que a contribuição dessas centrais para aumentar a coleta seletiva continua aquém do esperado. Caso as duas unidades tivessem atingido a produção nominal, a coleta seletiva alcançaria, em 2019, cerca de 180 mil toneladas, longe das pouco mais que 80 mil toneladas de fato coletadas nesse ano (São Paulo, 2020). A análise ora apresentada, da operação das centrais em seu primeiro ano e meio de funcionamento, fornece elementos que ajudam a explicar por que essa produção não foi alcançada.

A reciclagem enfrenta importantes dificuldades, que reduzem sua eficiência e aumentam o custo, limitando sua ampliação (Campos, 2013; Varella, 2011). A triagem manual aparece como principal gargalo, e a mecanização da triagem de resíduos como solução para o problema da escala. Tecnologias de mecanização da triagem, empregadas em plantas denominadas Material Recovery Facility (MRFs), são desenvolvidas em países centrais há pelo menos três décadas. MRFs ou Centrais Mecanizadas de Triagem (CMTs) - como ficaram conhecidas no Brasil - são sistemas de separação semimecanizados para recuperação em grande escala de materiais recicláveis (Ip et al., 2018; Kessler, 2009). Porém, o tratamento em CMTs afeta a qualidade (medida em grau de pureza) dos materiais destinados à comercialização. Esse problema vem se agravando nos últimos anos com o aumento do rigor das normas de comércio internacional de países que historicamente recebiam resíduos de baixa qualidade, como a China e a Indonésia (Brooks et al., 2018; Ip et al., 2018; Staub, 2017) ${ }^{2}$. Países que empregam de forma intensiva a mecanização da triagem dependem desses mercados mais tolerantes, e agora se vêm reféns dessa nova conjuntura.

Este artigo, com base em um estudo de caso de implantação em São Paulo de uma CMT projetada na Europa, discute por que as grandes centrais mecanizadas são inadequadas para a reciclagem e sugere uma alternativa que mescla de outra maneira atividade humana e máquinas automatizadas. A transferência de uma tecnologia desenvolvida e operada na Europa para um país periférico funcionou como um "quase-experimento" que permitiu evidenciar, como se fossem lupas, as causas dos problemas

\footnotetext{
${ }^{1}$ A pesquisa que subsidiou este artigo foi realizada entre os anos de 2014 e 2015, logo após a inauguração das Centrais Mecanizadas de Triagem, em julho de 2014. A utilização de dados de 2012, presentes no Plano de Gestão Integrada de Resíduos Sólidos de São Paulo, vigente à época, é intencional e serve para caracterizar a situação da gestão de resíduos recicláveis no município, na qual se decidiu pela implantação dessa tecnologia.

2 Muitas MRFs dependiam de mercados permissivos, por exemplo, os de papéis mistos, situação alterada a partir de 2013 com o estabelecimento da política chinesa conhecida como China's Green Fence. A China estipulou em novembro de 2017 um limite de contaminação de $0,5 \%$ para a maior parte dos recicláveis, o que equivale a banir a importação de alguns materiais. Outros países, como Indonésia e Vietnã, também colocaram limites e políticas parecidos.
} 
de eficiência e qualidade das CMTs, que persistem mesmo nos países centrais (Boudra, 2016; Miranda et al., 2013). Iniciamos introduzindo um quadro teórico no qual nos apoiamos para as reflexões acerca da transferência de tecnologia. No item 3 apresentamos o percurso metodológico da pesquisa, que se apoiou na antropotecnologia e na Análise Ergonômica do Trabalho (AET), para analisar as situações específicas dentro do estudo de caso. 0 caso das CMTs implantadas em São Paulo (item 4) evidencia problemas relacionados ao ambiente externo (coleta seletiva e mercado da reciclagem), ao processo produtivo interno (funcionamento dos equipamentos, condições de trabalho dos triadores) e aos resultados (eficiência e qualidade). Os problemas deste caso de transferência de tecnologia são retomados à luz do conceito de "antropotecnologia" de Alain Wisner (1985), cuja adoção leva à concepção de projetos mais aderentes à realidade dos países de destino (item 5). Concluímos (item 6) com sugestões de reprojeto desses sistemas, de modo a reduzir as pretensões da mecanização e automação na substituição do trabalho humano, propondo sistemas integrados homens-máquinas que resultem em melhor desempenho global e qualidade da produção.

\section{Transferência de tecnologia e antropotecnologia}

A transferência de tecnologia de países centrais para países periféricos é estudada há muito tempo nos mais diferentes tipos de indústria (Abrahão, 1985; Geslin, 2017; Ong, 1991; Pietrobelli, 2018; Wisner, 1981; 1985). Transferência tecnológica é o processo de introdução de determinado conhecimento tecnológico existente onde ele não foi originalmente concebido ou executado (Ong, 1991). Uma transferência de tecnologia inclui não só a máquina e os produtos, mas também os saberes, o know-how, procedimentos científicos e técnicos etc. (Pietrobelli, 2018; Wisner, 1985).

A estratégia de mimetizar tecnologias de tratamento de resíduos do Norte levou a investimentos caros e malsucedidos, de sistemas de compostagem a incineradores (Durand et al., 2019a). Toda transferência de tecnologia é (ou deveria ser) um processo de reprojeto. Uma ideia corrente é que o projeto define precisamente um problema, que será então resolvido pelos projetistas. Porém, nenhum problema é totalmente explicitado do momento da formalização da demanda e nem sempre o cliente ou seu interlocutor é o usuário direto de uma tecnologia (Duarte et al., 2008). Essa ideia comum é acompanhada ainda da tendência da engenharia e da organização industrial de separar a concepção da produção, projetando espaços e tecnologias de acordo com modelos distantes da realidade do usuário. Acontece que o projeto adequado se define pelo "ajuste" do artefato ao contexto (Alexander, 1964), que inclui também o contexto social (Freyssenet, 1992; Mackenzie \& Wajcman, 1999). Todo especialista que projeta um sistema o faz levando em consideração o uso que se fará do mesmo, em condições ou por pessoas que ele crê conhecer (Wisner, 1994). Sistemas técnicos são "objetivações humanas" ao serem o produto de uma reconstrução do sentido intencional que os humanos lhes deram e dão ao produzi-los e utilizá-los (Vandenberghe, 2010). 0 seu projeto é influenciado por diferentes visões de mundo, mesmo que implicitamente, cristalizadas pelo processo de formação e pela experiência prática dos projetistas. 0 problema de escopo mal definido acontece em todos os tipos de projeto, sendo uma das principais fontes de dificuldades na interação projetista-usuário (Ferreira \& Lima, 2006). Em transferências tecnológicas, esse problema tende a se agravar, uma vez que os projetistas são estrangeiros que pouco conhecem da realidade do país comprador. Associado a isso, os representantes do comprador (geralmente gerentes) desconhecem como o tecido social e uma dada tecnologia se entrelaçam e determinam seu funcionamento, o que permanece em parte tácito mesmo para os atores locais (Collins, 2011). Assim, os problemas de transferência de tecnologia podem ser tratados como um caso particular de uma categoria mais geral de problemas: o desajuste dos artefatos técnicos às condições em que devem operar, que resulta da desconsideração do caráter singular das situações de trabalho, tornando imprescindível o trabalho humano na "pavimentação" do caminho das máquinas, e isso mesmo em sistemas automatizados (Collins, 1990; Lima, 2005). 
Wisner desenvolveu a antropotecnologia partindo da premissa de que a tecnologia deve se adaptar às características do contexto onde será implementada. Nesse sentido, toda máquina é cultural e está inserida em um contexto geográfico e em tecidos sociais e industriais específicos, que permitem (ou dificultam) o seu funcionamento. Seria necessário, então, uma detalhada investigação prévia desses elementos no sentido de conduzir melhor as transferências de tecnologia para os países periféricos (Wisner, 1985). É o projeto das plantas industriais em sua totalidade - bem como dos processos a montante e a jusante - que devem ser (re)considerados no intuito de prover um ambiente favorável às máquinas (Akrich et al., 2002). A antropotecnologia pretende, então, intervir em processos de transferência de tecnologia entre países e culturas diferentes, contribuindo na antecipação das discrepâncias (sempre) existentes entre atividade prescrita e atividade real, minimizando as consequências negativas dessas transferências para indivíduos, comunidades e organizações (Geslin, 2017).

Qualquer "máquina inteligente" ou automática é uma "prótese social" (Collins, 1990) que, para funcionar, depende de uma série de elementos técnicos, sociais e culturais da rede sociotécnica onde está circunscrita, e que "[...] se integra à teia de atividades na qual todas as outras atividades humanas estão imersas [...]" (Ribeiro \& Collins, 2007, p. 1418). 0 funcionamento de máquinas é baseado em regras, que necessariamente possuem algum grau de generalidade, mas que "[...] contrapõe-se, na operação de sistemas complexos, a singularidade dos eventos e sua temporalidade presente e futura. Este campo de atividades de perceber e tratar a singularidade, até prova em contrário, permanece exclusivo aos homens" (Lima, 2005, p. 59).

Devido a essa exclusividade, é sempre a atividade humana que torna possível o funcionamento das máquinas, como será possível verificar empiricamente nas situações analisadas na CMT.

\section{Métodos e técnicas}

A pesquisa empreendida para elaboração do artigo se apoiou na metodologia de análise antropotecnológica para tecnologias transferidas (Wisner, 1985), com base na Análise Ergonômica do Trabalho (Guérin et al., 2001). A estratégia metodológica consiste em comparar uma dada tecnologia implantada em países ou regiões diferentes, para evidenciar o processo de adaptação tecnológica. No nosso caso, a análise mais aprofundada foi feita a partir do acompanhamento sistemático das situações de trabalho pós implantação das Centrais Mecanizadas de Triagem (CMTs) em São Paulo. Algumas características do funcionamento das centrais na França e em São Francisco (EUA) foram obtidas por meio de visitas técnicas de curta duração e de forma mais sistemática pela literatura especializada (Boudra, 2016).

No caso brasileiro, além da observação direta e entrevistas semiestruturadas realizadas nas próprias centrais, também foram feitos acompanhamentos de atividades diretamente à montante (coleta seletiva, atividades de sensibilização e educação ambiental etc.) e atividades a jusante (processo de vendas, contato com compradores, seminário de associações de recicladores etc.). Foram realizadas também visitas técnicas aos galpões de triagem manual das cooperativas que atuavam nas CMTs de São Paulo. No total, foram 125 horas de pesquisa de campo para realizar esse estudo de caso.

\section{As CMTs em São Paulo}

O Plano de Gestão Integrada de Resíduos Sólidos Urbanos de São Paulo visa atender a hierarquia estabelecida na Política Nacional de Resíduos Sólidos (PNRS), similar àquelas adotadas mundialmente. Para cada tipo de resíduo são traçadas estratégias visando o máximo reaproveitamento e reciclagem (Vieira et al., 2019). A Figura 1 ilustra a situação da reciclagem antes da implementação das CMTs. 


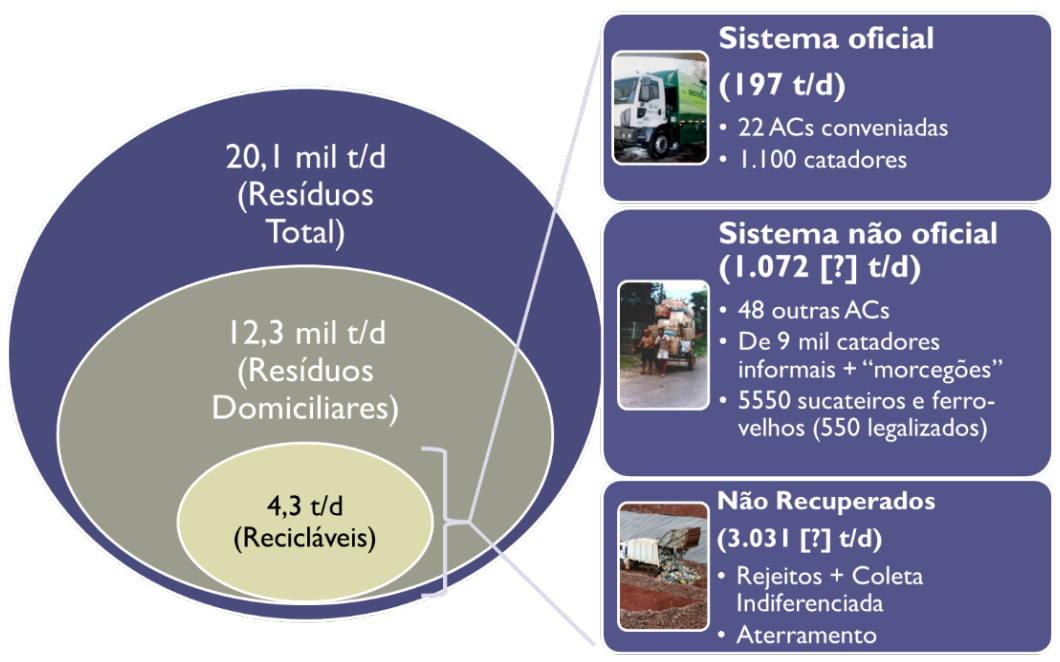

Figura 1 - Situação da reciclagem em São Paulo antes da implantação das CMTs. Fonte: elaboração própria a partir de São Paulo (2014).

A coleta seletiva em São Paulo adota o modelo porta a porta, amplamente disseminado no Brasil, em que caminhões percorrem as ruas coletando os materiais disponibilizados pela população. Os moradores devem separar os resíduos em duas categorias e apresentá-los em dias distintos: não recicláveis e recicláveis ("plásticos, vidros, metais e papéis", conforme orientação da Prefeitura). Os materiais coletados na coleta seletiva oficial são enviados às cooperativas e associações de catadores, onde são triados e comercializados no mercado interno de reciclagem. Esse mercado trabalha com critérios de qualidade, como: pureza do tipo de material, uniformidade da cor do material e ausência de materiais que possam prejudicar os processos industriais dos compradores, que exige uma separação criteriosa, reduzindo o custo de processos de retriagem fina nas empresas recicladoras (CMRR, 2012). Diferentemente de países europeus e dos EUA, no Brasil chega-se a separar 60 tipos de materiais recicláveis, dentre os quais 38 tipos de plásticos (Campos, 2013), e alguns materiais chegam a ser inseridos diretamente no processo de produção da recicladora (CMRR, 2012) ${ }^{3}$.

É nesse contexto que São Paulo tornou-se, em 2014, a primeira cidade da América Latina a implantar unidades semiautomatizadas de triagem de resíduos como principal opção para aumento da escala da reciclagem. Os projetos dessas plantas foram feitos por empresas europeias e os equipamentos são de origem alemã e francesa. A Central Mecanizada de Triagem 01 (CMT-01), sobre a qual focou-se a pesquisa, era operada por duas organizações: uma cooperativa de catadores (COOP), que lida com a parte operacional, e uma concessionária de limpeza urbana, responsável pela manutenção e controle remoto da planta. Ambas as organizações prestavam contas à Autarquia Municipal de Limpeza Urbana, órgão da gestão municipal responsável pela formulação e execução das políticas públicas de resíduos.

A pesquisa realizada na CMT-01 será apresentada em três partes: i) funcionamento prescrito das CMTs; ii) funcionamento real das CMTs; e iii) consequências gerais da mecanização da triagem. Em alguns pontos são evocados exemplos das outras experiências pesquisadas (MRFs de São Francisco e francesas) para ressaltar diferenças regionais.

\section{O funcionamento prescrito da CMT-01}

Alguns conceitos presentes na literatura ajudam na compreensão dos processos das CMTs. A tabela 1 resume essas categorias:

\footnotetext{
${ }^{3} \mathrm{~A}$ título de comparação, uma CMT francesa segrega 7 a 8 tipos de materiais, o que acontece em consequência da forma de organização do sistema de coleta seletiva e comercialização dos materiais (Boudra, 2016).
} 
Tabela 1 - Categorias de diferenciação de CMTs

\begin{tabular}{|c|c|c|c|}
\hline Instalações & Variável & Categorias & Explicação \\
\hline \multirow{6}{*}{ Planta } & Separação na & "Limpa" & Recebe resíduos com algum tipo de separação prévia. \\
\hline & fonte & "Suja" & Recebe resíduos sem nenhuma separação prévia. \\
\hline & Fluxo de & Fluxo único & A central possui apenas uma entrada de materiais. \\
\hline & entrada & $\begin{array}{l}\text { Fluxo duplo ou } \\
\text { múltipo }\end{array}$ & $\begin{array}{c}\text { A central possui duas ou mais entradas de materiais, } \\
\text { que seguem fluxos paralelos. }\end{array}$ \\
\hline & & Centralizada & $\begin{array}{l}\text { O trabalho de triagem manual é concentrado em um } \\
\text { único ponto, geralmente ao fim da linha. }\end{array}$ \\
\hline & manual & & $\begin{array}{c}\text { O trabalho de triagem manual é distribuído ao longo } \\
\text { da linha, em dois ou mais pontos. }\end{array}$ \\
\hline $\begin{array}{l}\text { Elementos } \\
\text { mecânicos }\end{array}$ & Direção do & Acima (over) & $\begin{array}{c}\text { Fluxo de materiais que passam pela máquina sem } \\
\text { sofrer atuação do elemento de separação mecânica } \\
\text { (ex.: materiais que passam pela peneira rotatória sem } \\
\text { cair em nenhum orifício). }\end{array}$ \\
\hline $\begin{array}{c}\text { de } \\
\text { separação }\end{array}$ & & Abaixo (under) & $\begin{array}{l}\text { Fluxo de materiais que sofre atuação direta do } \\
\text { elemento de separação da máquina (ex.: materiais } \\
\text { que caem pelo orifício da peneira rotatória). }\end{array}$ \\
\hline $\begin{array}{l}\text { Elementos } \\
\text { digitais de }\end{array}$ & Lógica de & Positiva & $\begin{array}{l}\text { O trabalhador/atuador age sobre o material que se } \\
\text { deseja separar, retirando-o do fluxo. }\end{array}$ \\
\hline $\begin{array}{l}\text { separação e } \\
\text { triagem } \\
\text { humana }\end{array}$ & $\begin{array}{l}\text { separação/ } \\
\text { triagem }\end{array}$ & Negativa & $\begin{array}{c}\text { O trabalhador/atuador deixa passar o material que se } \\
\text { deseja separar e age sobre outros materiais, } \\
\text { "limpando" o fluxo. }\end{array}$ \\
\hline
\end{tabular}

Fonte: elaboração própria a partir de Kessler (2009).

A CMT-01 é uma central "limpa", de fluxo único e com triagem manual centralizada, dividida em cinco linhas: 1) separação mecânica; 2) classificação ótica; 3) triagem manual; 4) prensa enfardadeira e 5) linha centralizadora do refugo. A Tabela 2 fornece uma breve explicação sobre essas linhas, suas máquinas e seu funcionamento prescrito.

Tabela 2 - Descrição do funcionamento prescrito das linhas da CMT-01

\begin{tabular}{|c|c|c|}
\hline Linha & Equipamento & Funcionamento prescrito \\
\hline Comum a todas as linhas & $\begin{array}{l}\text { Esteiras transportadoras } \\
\text { Rasga-sacos }\end{array}$ & $\begin{array}{l}\text { Transporte dos resíduos entre equipamentos. } \\
\text { Abertura mecânica dos sacos. }\end{array}$ \\
\hline \multirow[t]{4}{*}{$\begin{array}{l}\text { Linha de separação } \\
\text { mecânica }\end{array}$} & Trommel (T) & $\begin{array}{l}\text { Peneira giratória que separa o resíduo por tamanho: } \\
\text { PEQUENOS ( } \varnothing<90 \mathrm{~mm} \text {, fluxo under), MÉDIOS ( } 90<\varnothing<250 \mathrm{~mm} \text {, } \\
\text { fluxo under) e GRANDES ( } \varnothing>250 \mathrm{~mm} \text {, fluxo over). } \\
\text { Separa o material MÉDIO de (T) por pesos e formatos: } 2 D \text { (fluxo }\end{array}$ \\
\hline & Separador balístico (B) & $\begin{array}{c}\text { over), 3D (fluxo under) e MUITO PEQUENOS ( } \varnothing<45 \mathrm{~mm} \text {, fluxo } \\
\text { under). }\end{array}$ \\
\hline & $\begin{array}{l}\text { Separador óticos 2D-1 } \\
\text { (SO-2D-1) }\end{array}$ & $\begin{array}{c}\text { Recebe o fluxo 2D de (B) e separa plástico filme (triagem } \\
\text { positiva) do restante (triagem negativa). }\end{array}$ \\
\hline & $\begin{array}{l}\text { Separador óticos 2D-2 } \\
\text { (SO-2D-2) }\end{array}$ & $\begin{array}{l}\text { Recebe o fluxo under do (SO-2D-1) e separa papelão (triagem } \\
\text { positiva) do restante (triagem negativa). }\end{array}$ \\
\hline \multirow[t]{2}{*}{$\begin{array}{l}\text { Linha de classificação } \\
\text { ótica }\end{array}$} & $\begin{array}{l}\text { Separador óticos 3D-1 } \\
\text { (SO-3D-1) }\end{array}$ & $\begin{array}{c}\text { Recebe o fluXO 3D de (B) e separa polietileno de alta } \\
\text { densidade - PEAD e polipropileno - PP (triagem positiva), } \\
\text { polietileno tereftalato - PET (triagem positiva) e o restante } \\
\text { (triagem negativa). }\end{array}$ \\
\hline & $\begin{array}{l}\text { Separador óticos 3D-2 } \\
\text { (SO-3D-2) }\end{array}$ & $\begin{array}{l}\text { Recebe o fluxo PET do (SO-3D-1) e separa PET verde (triagem } \\
\text { positiva, fluxo over), PET colorido (triagem positiva) e PET incolor } \\
\text { (triagem negativa). }\end{array}$ \\
\hline \multirow[t]{2}{*}{ Linha de triagem manual } & $\begin{array}{l}\text { Cabine de triagem } \\
\text { manual }\end{array}$ & $\begin{array}{l}\text { Os catadores atuam nessa cabine, segundo o projeto apenas } \\
\text { para controle de qualidade. Composta de oito esteiras, que } \\
\text { recebem os materiais das sub-linhas mecanizadas. }\end{array}$ \\
\hline & Silos automáticos & $\begin{array}{l}\begin{array}{l}\text { Compartimentos onde os materiais são armazenados depois } \\
\text { de triados. }\end{array}\end{array}$ \\
\hline Linha prensa enfardadeira & Prensa & $\begin{array}{c}\text { Transforma os materiais dos silos em FARDOS. O controle é } \\
\text { predominantemente remoto. }\end{array}$ \\
\hline \multirow{2}{*}{$\begin{array}{l}\text { Linha centralizadora do } \\
\text { refugo }\end{array}$} & Separador magnético & $\begin{array}{l}\text { A partir de uma esteira magnética, separa materiais ferrosos } \\
\text { (fluxo under). }\end{array}$ \\
\hline & Separador por indução & $\begin{array}{l}\text { A partir de um tambor de indução, separa metais não ferrosos } \\
\text { (fluxo over). }\end{array}$ \\
\hline
\end{tabular}

Fonte: descritivo de processo da CMT-01. 


\section{O funcionamento real da CMT-01}

Observações de campo permitiram identificar uma série de situações operacionais que mostram o funcionamento da CMT-01 para além do que está prescrito no projeto, que podem ser agrupadas em quatro categorias relacionadas: 1) aos materiais de entrada, 2) aos próprios equipamentos, 3) às inadequações antropométricas e 4) ao leiaute e fluxo produtivo. Em todos eles podemos notar tanto inadequações derivadas de características dos próprios equipamentos ou do projeto quanto problemas originados nas interfaces entre equipamentos e o tecido social e técnico mais amplo.

\section{Materiais: o vidro e o polipropileno}

O vidro é coletado em conjunto com os demais materiais recicláveis, e não existe projeto para coleta diferenciada desse material. A CMT-01 foi projetada sem considerar processos para recuperação do vidro; segundo o gerente de operações, estudos realizados concluíram a inviabilidade econômica da sua recuperação ${ }^{4}$.

Na CMT-01 existem várias transições em desnível, entre esteiras e de esteiras para equipamentos, provocando a quebra do vidro, que percorre todo o processo. 0 vidro quebrado é causa de rasgos de correias, que podem levar a longas paradas na planta; é um material abrasivo, que desgasta equipamentos e borrachas das correias transportadoras, diminuindo sua vida útil 5 ; e aumenta a taxa de refugo da planta, ao não ser recuperado. Gera também dificuldades para os clientes, alguns tendo relatado sérios problemas em seus equipamentos em razão da quantidade de vidro moído nos fardos. Eles utilizam filtros especiais em seus processos produtivos, que foram danificados por cacos de vidro.

Outros problemas estão relacionados ao polipropileno (PP), que representa aproximadamente $10 \%$ dos plásticos presentes no resíduo doméstico brasileiro (CMRR, 2012). Apesar de ser identificado e separado pelo SO-3D-1, o PP não é aproveitado na planta. Mesmo assim ele é encaminhado junto com o PEAD branco, para uma esteira de triagem negativa, gerando um trabalho adicional para as triadoras retirá-los do fluxo. Essa esteira possui um fluxo abundante de material e uma alta exigência de qualidade, intensificando o ritmo de trabalho.

\section{Equipamentos: as máquinas enfrentam o mundo}

A eficiência das máquinas é impactada por situações imprevistas, para além das limitações técnicas inerentes às máquinas, isto é, aquelas assumidas pelos seus vendedores e colocadas nos manuais em formas de parâmetros, set points e limites de tolerância. São os trabalhadores que criam e adotam estratégias operatórias para melhorar a eficiência de cada equipamento e de todo o sistema da planta, como pode ser visto no caso do trommel e dos Separadores Óticos (SOs). Essas máquinas são comuns em centrais mecanizadas, mesmo nos países centrais (Kessler, 2009), o que nos permite generalizar os problemas aqui relatados.

0 trommel possui orifícios cuja obstrução, parcial ou total, reduz sua eficiência. A grande incidência de certos objetos, principalmente de materiais "enroscantes", no fluxo tornou a desobstrução dos orifícios uma tarefa rotineira da manutenção ${ }^{6}$. Segundo o gerente de manutenção (doravante GMAN01), a ocorrência de obstruções no equipamento aumenta o rejeito em até $10 \%$ porque os objetos menores

\footnotetext{
${ }^{4}$ Ressalta-se que sistemas com a segregação do vidro na fonte são muito comuns em países europeus, especialmente na França, país vendedor da tecnologia na CMT-01, onde 93\% da população tem acesso à coleta seletiva de vidro (Djemaci, 2009).

${ }^{5}$ Esse fenômeno também é observado nas CMTs instaladas em São Francisco e na cidade de Lille, uma das poucas cidades francesas sem coleta separada do vidro.

${ }^{6}$ Qualquer material longo e com alguma resistência à quebra ou rompimento pode ser enquadrado nessa categoria de materiais "enroscantes", por exemplo bobinas de fitas de vídeo e fitas K-7, linhas, cordões, fios, cabos e têxteis longos.
} 
tendem a passar no fluxo over. Se objetos médios (garrafas PET, caderno, sacolas...) não caem em algum dos orifícios médios, eles acabarão no fluxo dos objetos grandes e encaminhados para a esteira de triagem manual. Nessa esteira, a densidade do fluxo de material é alta, e os catadores focam em objetos grandes, mais fáceis de triar em tempo hábil. Os materiais médios fatalmente seguirão para a linha de refugo, virando rejeito. Fenômeno parecido se dá quando da formação de "bolos", como chamou GMAN01, que são aglomerados de materiais em torno de um material "enroscante" no trommel (Figura 2). Esses aglomerados tornam impossível a separação do material, tanto nos equipamentos quanto na linha de triagem manual.

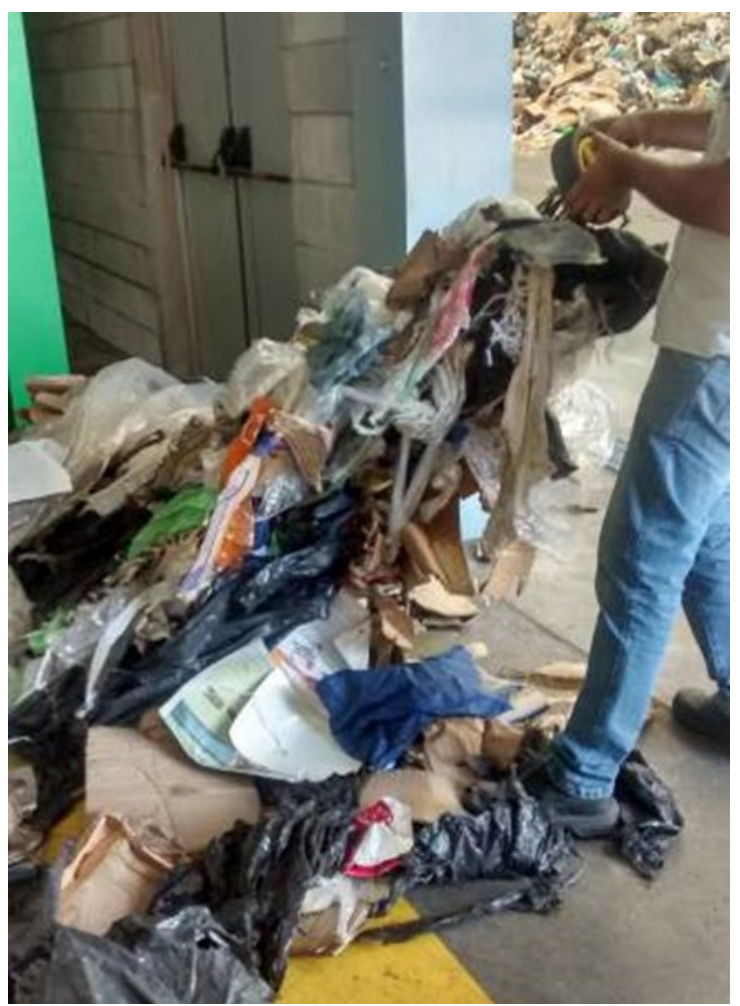

Figura 2 - Exemplo de "bolo", formado por uma extensão elétrica. Fonte: registro fotográfico do autor (março de 2015).

Em relação aos SOs, três principais variáveis interferem em seu funcionamento: densidade do fluxo de entrada, disponibilidade do leitor infravermelho e obstruções nas réguas de sopro. 0 bom funcionamento dos SOs exige que o fluxo de materiais seja bem distribuído e pouco denso, ou seja, que poucos materiais passem na frente do leitor infravermelho, para possibilitar a identificação ${ }^{7}$. Existem situações, porém, em que um grande volume de resíduos passa pelo fluxo, e o equipamento não consegue identificar todos, como sacolas que passam inteiras com materiais em seu interior e plásticos ou papéis que encobrem outros materiais.

Materiais longos por vezes enroscam no equipamento e prendem outros materiais, bem em frente ao leitor infravermelho do equipamento, impedindo completamente sua funcionalidade. A consequência imediata é a chegada de materiais, sem nenhuma classificação, nas esteiras de triagem manual que recebem os fluxos negativos dos SOs. Outra causa de mau funcionamento é a presença de líquidos que podem derramar na proteção de acrílico dos leitores, prejudicando a passagem dos feixes de infravermelho; como no caso de uma lata com tinta que derramou parte de seu conteúdo sobre esse leitor.

Por fim, as réguas de sopros estão sujeitas ao entupimento de seus orifícios, que impede a passagem de ar e consequentemente a ejeção dos materiais identificados. Isso é provocado por papéis e plásticos

\footnotetext{
${ }^{7}$ Isso é válido inclusive para os separadores óticos mais recentes e avançados tecnologicamente, que funcionam com detecção multimaterial e braços robóticos para a separação.
} 
que agarram em frente à régua (figura 3) e por restos de líquidos presentes no interior de embalagens (como cervejas, produtos de limpeza), que derramam e entopem os orifícios da régua. Esses problemas são frequentes, impactando principalmente a regularidade e a qualidade da separação de materiais como PET e PEAD.

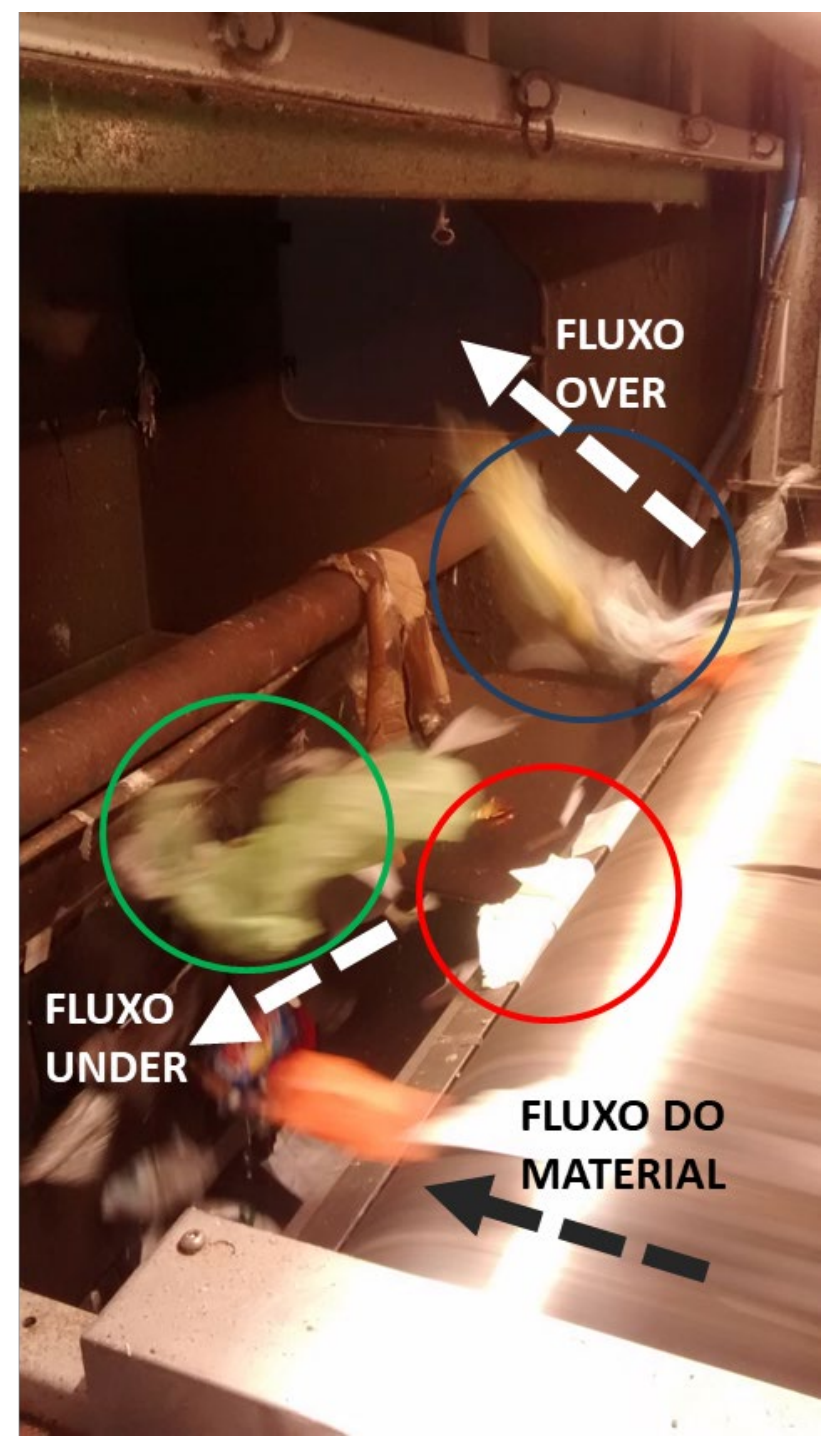

Figura 3 - Obstrução da régua de sopro no SO-2D-1. Fonte: registro fotográfico do autor (novembro de 2015). Nota: No círculo vermelho destacamos um pedaço de papel bloqueando a passagem de ar na régua de sopro. O círculo azul destaca um plástico filme sendo ejetado pela régua de sopro (fluxo over). O círculo verde destaca um plástico filme caindo no fluxo negativo (under), devido ao bloqueio da saída de ar da régua de sopro pelo papel.

\section{Postos de trabalho nas esteiras de triagem}

Outro caso de inadequação do projeto é o dos postos de trabalho. As esteiras de triagem manual foram projetadas para uma população de trabalhadores mais alta que a média brasileira. As esteiras na CMT-01 têm 1,12 m de altura, com larguras variáveis. A conjunção dessas medidas, dada a altura média dos catadores que trabalham na central - $981 \pm 46 \mathrm{~mm}$, de altura entre o piso e o cotovelo fletido -, traz efeitos importantes para os trabalhadores. Os materiais que passam no centro das esteiras não são 
alcançados, mesmo trabalhando com os braços esticados e flexão da coluna (como pode ser visto na Tabela 3 e na Figura 4), postura impossível de se manter por períodos prolongados.
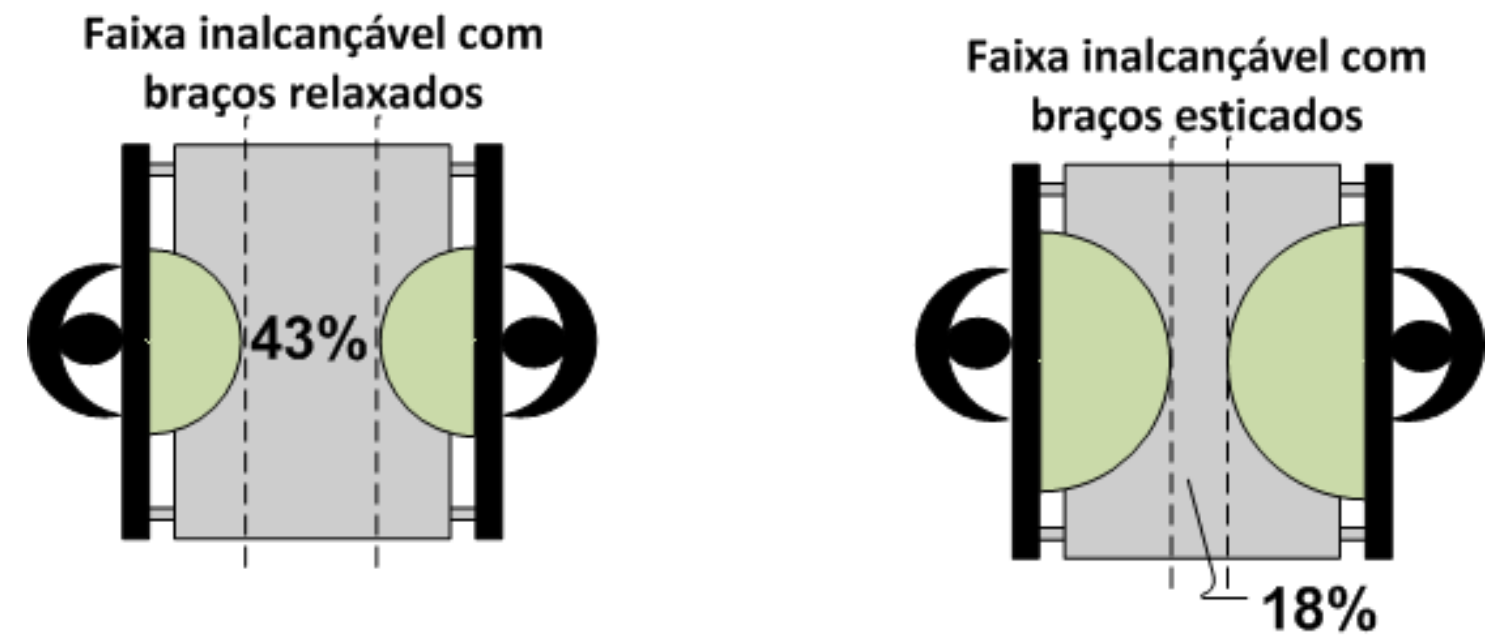

Figura 4 - Representação das faixas inalcançáveis na esteira E8. Fonte: elaboração própria.

Tabela 3 - Faixas inalcançáveis das esteiras

\begin{tabular}{|c|c|c|c|c|}
\hline Esteira & Configuração de trabalho & $\begin{array}{l}\text { Largura da } \\
\text { esteira }(\mathrm{mm})\end{array}$ & $\begin{array}{l}\text { Faixa inalcançável com } \\
\text { braços relaxados (mm - \% } \\
\text { da largura da esteira) }\end{array}$ & $\begin{array}{l}\text { Faixa inalcançável com } \\
\text { braços esticados ( } \mathrm{mm} \text { - } \\
\% \text { da largura da esteira) }\end{array}$ \\
\hline El & $\begin{array}{l}\text { Catadores em ambos os lados } \\
\text { da esteira, frente a frente }\end{array}$ & 1.430 & $498-35 \%$ & $70-5 \%$ \\
\hline E2 & $\begin{array}{c}\text { Catadores em apenas um lado } \\
\text { da esteira }\end{array}$ & 920 & $560-61 \%$ & $290-32 \%$ \\
\hline E3 & $\begin{array}{c}\text { Catadores em ambos os lados } \\
\text { da esteira, alternados }\end{array}$ & 1.000 & $607-61 \%$ & $400-40 \%$ \\
\hline E4 & $\begin{array}{c}\text { Idem E2 } \\
\text { Esteira de dois fluxos. Catadores }\end{array}$ & 1.030 & $590-57 \%$ & $440-43 \%$ \\
\hline E5 & $\begin{array}{l}\text { em ambos os lados da esteira, } \\
\text { cada um em um fluxo }\end{array}$ & 1.860 & $480-26 \%$ & $310-17 \%$ \\
\hline E6 & Idem El & 1.450 & $497-34 \%$ & $83-6 \%$ \\
\hline E7 & Idem El & 1.450 & $517-36 \%$ & $150-10 \%$ \\
\hline E8 & Idem El & 1.580 & $675-43 \%$ & $285-18 \%$ \\
\hline
\end{tabular}

Fonte: dados da pesquisa.

As faixas inalcançáveis influenciam diretamente no aumento do rejeito e na diminuição da qualidade, principalmente nas esteiras com fluxo mais denso. É o caso da esteira E1, onde a triagem é positiva e o material inalcançável vai para o rejeito; e da esteira E8, onde a triagem é negativa e o material inalcançável passa para o silo de papel misto, interferindo na qualidade do produto.

\section{Leiaute e fluxo: os funis inservíveis}

Por fim, a estrutura das CMTs é também inadequada para o processo de trabalho real no interior das cabines de triagem manual. Um sintoma dessa inadequação é a quantidade de funis que não são utilizados pelos triadores ( 27 de 66, 41\%). Por exemplo, na esteira E1 de triagem positiva, que recebe os objetos grandes do trommel, existem 10 duplas de funis projetadas para receber praticamente todos os materiais que são processados na planta. Dessas 10 duplas, 4 foram inutilizadas: PET verde, PEAD colorido, PEAD branco e PET cristal, materiais que possuem critérios mais rigorosos de qualidade. Essa esteira recebe, às vezes, um fluxo muito denso de material, que pode ocasionar queda acidental de outros resíduos para dentro dos funis, afetando a qualidade da separação. 0 que é agravado pela posição desses funis no início 
do fluxo da esteira, onde ainda existem muitos materiais grandes, como caixas de papelão e plásticos filme, que tendem a esconder os materiais menores, como os quatro supra citados, dificultando a identificação. Para evitar uma perda ainda maior desses materiais, os catadores improvisaram recipientes de armazenamento temporário no final da esteira, que depois são descarregados nos funis apropriados.

\section{Consequências gerais da mecanização da triagem}

Nesta seção apresentamos as consequências gerais da conjunção de problemas para a CMT analisada na pesquisa. Apesar de se tratar de uma análise focada em um caso, veremos que podem ser formuladas certas generalizações, que se aplicam a qualquer sistema mecanizado de triagem, o que nos ajudará, posteriormente, a formular propostas de reprojeto.

\section{Baixa qualidade do produto final}

Todos os produtos apresentam algum grau de impureza, gerando problemas de qualidade maiores ou menores na reciclagem. Na CMT-01, o papel misto e o ferro se destacam como materiais mais problemáticos em relação à qualidade. 0 papel misto representa cerca de $50 \%$ da produção da CMT-01, e o problema da baixa qualidade influencia diretamente no preço, no faturamento da central e na cadeia a jusante. Os responsáveis pela sua comercialização enfrentam dificuldades para encontrar compradores, que chegou a ser vendido por $R \$ 0,01 / \mathrm{kg}$, quando o preço de mercado era $R \$ 0,10 / \mathrm{kg}$. 0 principal problema de qualidade do papel misto é a presença de outros materiais que não papéis: a gravimetria realizada em fardos de papel misto revelam um percentual de mistura na casa dos $15 \%{ }^{8}$. A Figura 5 mostra um fardo de papel misto com significativa presença de materiais contaminantes.

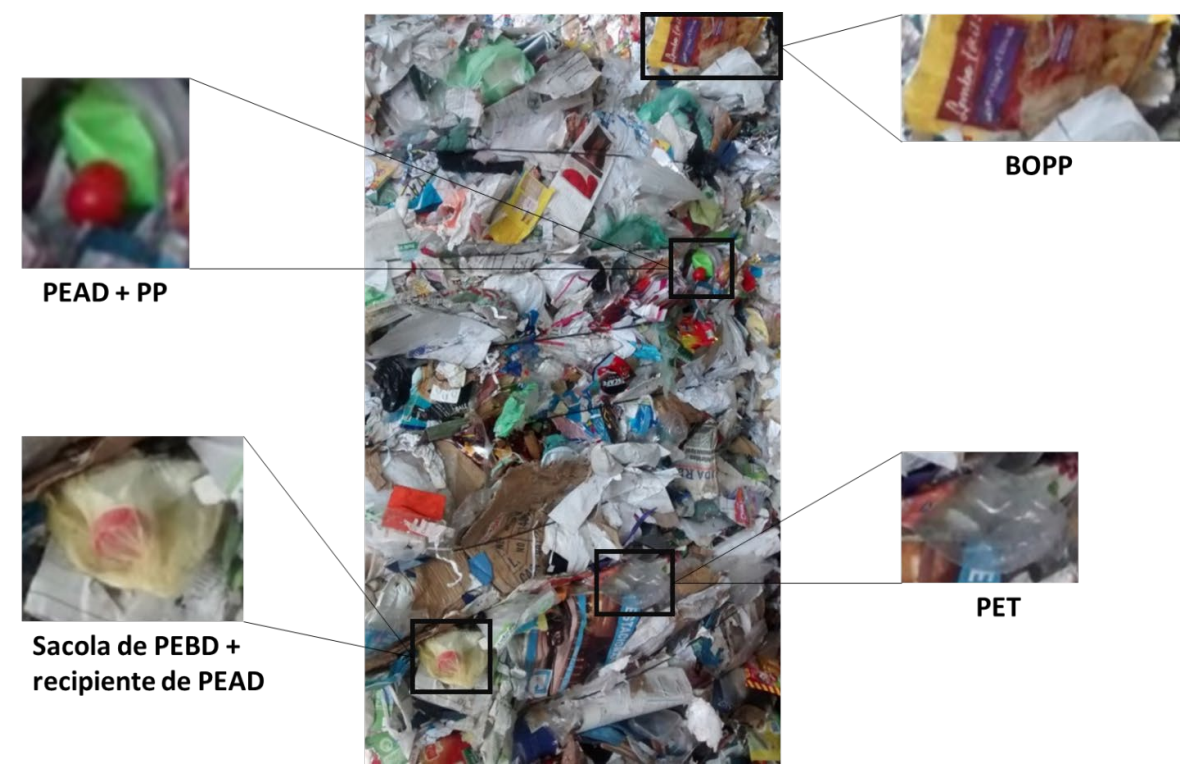

Figura 5 - Fardo de papel misto da CMT-01 com alto nível de contaminação. Fonte: registro fotográfico do autor (dezembro de 2015).

\footnotetext{
${ }^{8} \mathrm{Um}$ dos compradores afirmou que os fardos de papel misto adquiridos chegam a ter $40 \%$ de materiais contaminantes. A significativa diferença nos números pode ser explicada pela adoção de diferentes métodos de análise, de qualquer modo o nível de contaminação estava em níveis impeditivos. Para que se tenha uma referência, o último nível de contaminação estabelecido na China é de 0,5\% (Staub, 2017). No Brasil, o teor máximo de impureza permitido para papéis fica na casa dos 3\% (CMRR, 2012).
} 


\section{Alto índice de rejeito}

Um segundo problema é o alto índice de rejeito da planta, que fica próximo de $50 \%{ }^{9}$. Parte disso devese à separação inadequada na fonte ${ }^{10}$, mas além dos fatores externos existem causas internas nas CMTs que colaboram para essa proporção elevada, como o não processamento do vidro. Um estudo gravimétrico realizado em julho/2015 revelou que aproximadamente $40 \%$ dos materiais presentes no refugo eram vidro, índice maior que a soma da quantidade dos outros materiais considerados "não recuperáveis", que foi $36 \%{ }^{11}$. 0 restante do refugo (24\%) era formado por materiais passíveis de recuperação nessa planta ${ }^{12}$. A Figura 6 mostra a gravimetria realizada no rejeito.

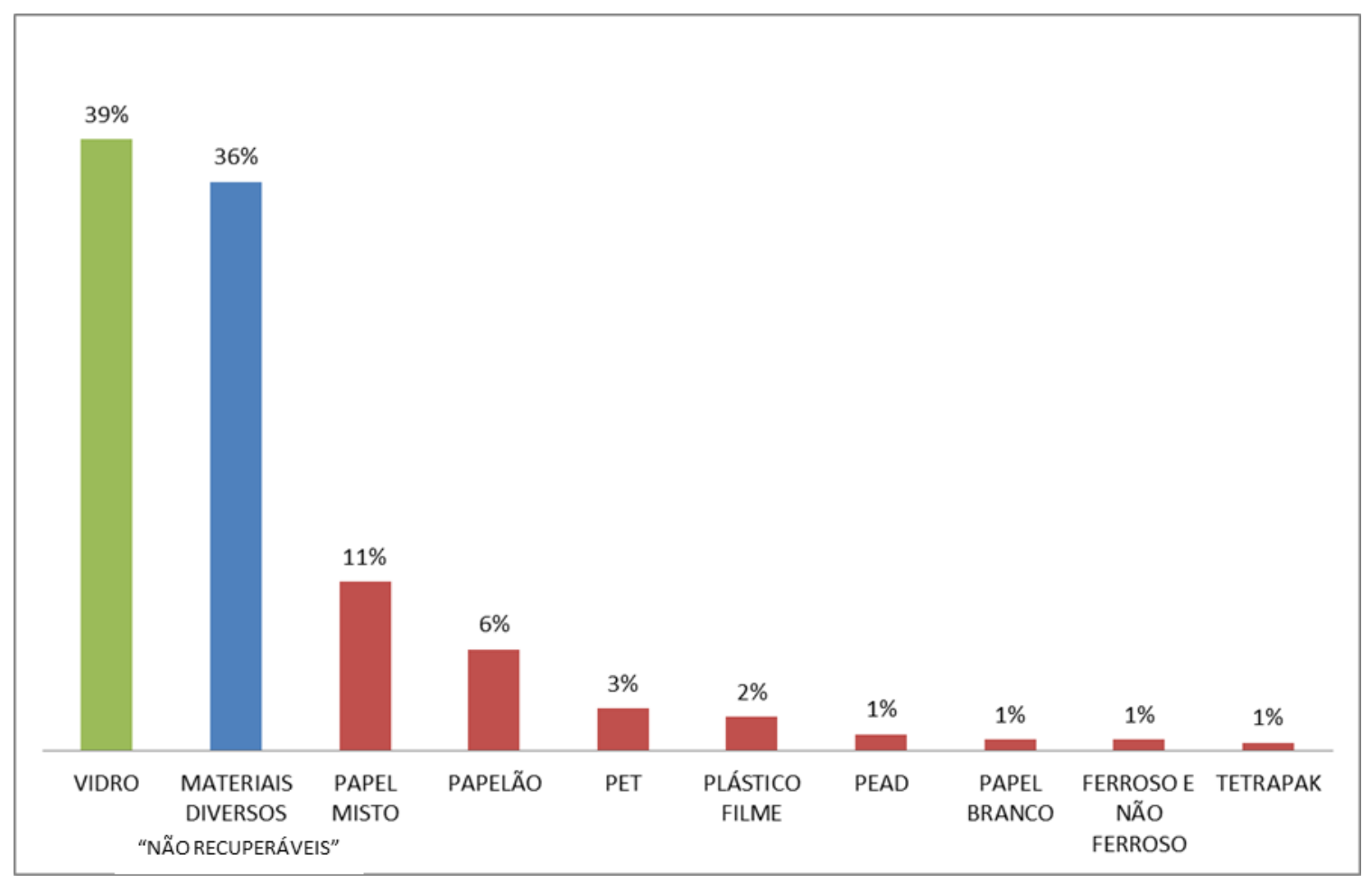

Figura 6 - Composição do rejeito na CMT-01. Fonte: gravimetria do rejeito realizada da CMT-01 em 16/7/2015.

\section{Precarização do trabalho e das condições de saúde e segurança}

O ritmo intenso do processo nas CMTs, associado à limitação das possibilidades de regulação do trabalho, gera efeitos colaterais negativos nos trabalhadores, principalmente nos mais idosos, que estão presentes em grande número nas associações e cooperativas de catadores (Oliveira, 2010). Na cabine de triagem manual a situação ainda é agravada pela necessidade de se trabalhar o tempo todo em pé, em cima de plataformas improvisadas (steps), a fim de compensar as inadequações antropométricas das esteiras.

\footnotetext{
${ }^{9}$ A CMT-01 foi projetada pelos exportadores da tecnologia para trabalhar com um índice de rejeito de 39\%, para se adequar à meta de $40 \%$ estabelecida pela municipalidade.

${ }^{10}$ Essa é também uma realidade nas ACs. Nas experiências em que a coleta seletiva é executada pelos próprios catadores, a separação na fonte tende a ser melhor, devido aos vínculos que eles criam com a população no ato da coleta, conforme mostra Rutkowski \& Rutkowski (2015), no que elas chamam de "contato pessoal regular".

110 percentual de recicláveis no refugo é, na verdade, ainda maior, tendo em vista que nesse percentual estão incluídos todos os materiais recicláveis que a planta não consegue recuperar. Como não são passíveis de recuperação vários recicláveis, como PP, PVC e PS, parte dos $36 \%$ é formada por esses materiais.

12 Considerando que a CMT-01 tem um percentual de rejeito próximo de $50 \%$, caso se recuperassem o vidro e outros materiais passíveis de recuperação o rejeito cairia para cerca de $22 \%$.
} 
Existem problemas associados ao ritmo intenso de trabalho imposto pela alta velocidade da esteira. Os triadores sentem tontura, já houve um registro de desmaio por esses efeitos e alguns casos de acionamentos do botão de emergência.

Outro elemento de precarização do trabalho está presente nas esteiras que têm triagem negativa, pois elas implicam a manipulação de rejeitos como animais mortos, restos de comida, lixo de banheiro e até resíduos ambulatoriais, como seringas. Por fim, um problema especial na esteira E1 é a alta incidência de poeira nos materiais, que, ao serem manipulados, projetam em suspensão esses particulados.

\section{As CMTs são funcionais?}

O caso nas CMTs de São Paulo coloca duas questões principais: primeiro, as dificuldades que podem originar-se de uma transferência de tecnologia feita sem considerar os aspectos antropotecnológicos envolvidos; segundo, as limitações próprias da maquinaria, o que reforça a ideia de que máquinas e computadores não dispensam habilidades e julgamentos humanos.

É verdade que, nos países centrais onde foram inicialmente projetadas e implantadas, as MRFs funcionam mais ou menos bem sob certas condições ("funcionavam" melhor antes do China's Green Fence $)^{13}$. Conseguem cumprir o que prometem, ou seja, separar os materiais nas categorias que o tecido industrial estabelecido precisa.

À primeira vista, esses sistemas aparentam ter um funcionamento autônomo, contando com alguns trabalhadores humanos, que teriam a única função de controle de qualidade, ou seja, de corrigir mínimas imperfeições que as máquinas porventura deixam passar. Porém, uma análise mais cuidadosa revela que o funcionamento dessas máquinas dependem de complexas relações que conformam os sistemas sociotécnicos onde estão inseridas: nesse sentido, máquinas são "próteses sociais" (Collins, 1990) que precisam ser ajustadas ao corpo social onde se inserem, como o caso dos SOs, que dependiam da expertise dos catadores para identificar situações que ocasionavam seu mau funcionamento, como o entupimento da régua de sopro.

Os fornecedores, responsáveis pelo design da planta e pela especificação dos seus modos de operação, basearam-se em estudos de gravimetria dos resíduos recicláveis recolhidos na cidade. Esses projetistas, porém, desconsideraram diversos outros aspectos da realidade aos quais os sistemas iam se confrontar. Mesmo que a gravimetria tenha identificado todos os tipos de materiais que causam problemas nas CMTs, o uso que se faz dessa informação não chega a identificar efeitos que deveriam ser considerados no projeto dos equipamentos, como: avarias e desgaste acelerados de equipamentos devido à presença de vidro; não recuperação de PP; posicionamento de funis para materiais relativamente pequenos em comparação ao fluxo recebido na esteira E1; previsão de linha recuperadora de PET colorido, material sem reciclabilidade no tecido industrial brasileiro.

Como em outros casos de transferência de tecnologia, adotaram uma "visão universalista" para o projeto, ou seja, a visão da tecnologia como algo indiferente ao contexto sociopolítico. Ao assumir essa visão, os projetistas cristalizam na planta suas próprias noções de mundo, o que impacta diretamente no resultado dessas tecnologias e das "transferências". É precisamente esse o sentido da afirmação de que "toda máquina é cultural" (Wisner, 1992) e carrega em suas configurações regulações que as tornam ajustadas aos tecidos social e técnico em que operam. As máquinas precisam sempre dos cuidados dos trabalhadores, que criam um "micromundo" (Burton et al., 1984) em que elas conseguem funcionar.

Essa contribuição da atividade humana ao bom funcionamento dos sistemas sociotécnicos tende a se desenvolver de forma invisível mesmo nos países de origem. Os trabalhadores das centrais francesas enfrentam toda uma sorte de problemas similares aos que foram encontrados nas centrais brasileiras, $\mathrm{e}$

\footnotetext{
${ }^{13}$ Do ponto de vista local, as MRFs, que exportam os materiais para países periféricos na Ásia e Pacífico orientais, funcionavam mais ou menos bem. Mas, analisando a cadeia global, é preciso relativizar esse aparente bom funcionamento, que depende de funcionamentos precários em outras partes do mundo, ou, mais especificamente, no jargão da indústria estadunidense da reciclagem, do "apetite chinês" (China's appetite).
} 
têm estratégias de regulação para evitar ou minimizar os mesmos (Boudra, 2016), que permanecem escondidas na operação cotidiana. Esses conhecimentos e estratégias não são transportados com a central que é transferida, permanecendo confinados aos micromundos singulares de cada planta.

Como lidar com materiais "enroscantes"? E os materiais volumosos? Como lidar com o vidro? A baixa qualidade do papel misto, como fazer para minimizá-la? E os altos índices de materiais recicláveis no rejeito, existem "macetes" para diminuí-los? Como obter fluxos menos densos? Como lidar com entupimentos no trommel e bloqueios dos leitores dos SOs? Todas essas perguntas são importantes. Todavia, só são possíveis de serem formuladas e respondidas a partir da análise minuciosa do processo de produção e do trabalho. Em uma transferência de tecnologia com "visão universalista" elas jamais são feitas, uma vez que, supõem-se, "as máquinas funcionam por si só". Mas adotando uma abordagem mais cuidadosa, como a antropotecnologia, seria possível identificar esses problemas e as soluções inventadas, e, assim, tanto melhorar o projeto original quanto incorporar esses elementos na transferência. Para que uma transferência de tecnologia seja bem-sucedida, deveria ser precedida de análises de situações de referência: a mesma tecnologia ou tecnologia similar operando nos países de origem e em outros locais. Não para servir de benchmark, prática que opera ainda como uma abstração descontextualizada, separando a técnica do seu tecido social e de sua história evolutiva. Analisar situações de referência permite não apenas aprender com a experiência dos outros, mas também reconhecer que a tecnologia a ser transferida deve passar por um reprojeto.

Para além dessa discussão, resta ainda uma questão prática fundamental: essas tecnologias convencionais dos países centrais podem se adequar aos contextos dos países periféricos? Ou, mais especificamente, as CMTs são adequadas ao contexto brasileiro da reciclagem?

Respondemos parcialmente à questão contrapondo o desempenho previsto às ineficiências reais. Sem dúvida, as CMTs proporcionam ganhos de produção considerando o volume processado. No entanto, mesmo do ponto de vista da eficiência técnica, apresentam deficiências importantes, uma vez que ganham em eficiência produtiva em detrimento da qualidade e, consequentemente, com perda de eficiência no elo subsequente, dos compradores. Estes precisam adequar seus processos, reproduzindo condições precárias no trabalho para lidar com produtos de qualidade deteriorada, como vimos no caso do papel misto.

Do ponto de vista ambiental, as CMTs são mais eficientes que destinações ainda comuns no Brasil, como aterramento ou disposição a céu aberto. Porém, precisam também percorrer um longo caminho para serem consideradas ambientalmente eficientes, caminho que passa pela redução de rejeitos e pela melhoria da qualidade dos produtos.

Por fim, do ponto de vista social, a tecnologia pesquisada perde em eficácia se comparada à tecnologia social da Coleta Seletiva Solidária (Lima et al., 2011; Rutkowski \& Rutkowski, 2015). A máquina, se pensada exclusivamente em termos de ganhos de eficiência imediata, carrega o caráter excludente do mercado de trabalho formal, reduzindo a quantidade de pessoas empregadas e, nesse processo, excluindo os de menor desempenho, normalmente iletrados, mulheres, doentes e idosos, pessoas que as cooperativas de catadores acolhem, contrapondo-se ao caráter excludente da tecnologia de alto desempenho. Isso não quer dizer que a alternativa seja optar por processos manuais e máquinas de baixo desempenho ou baixa intensidade tecnológica. Os sistemas de gestão de RSU tendem, mais, a assumir formas mistas, combinando a high-tech do Norte com as low-tech do Sul, inclusive em processos de transferência em mão dupla (Durand etal., 2019b). É necessário usar o que de melhor existe da tecnologia para facilitar o trabalho de pessoas com capacidade reduzida devido a sua condição física e idade, sem reproduzir a exclusão à segunda potência (Lima et al., 2019). Os catadores, historicamente, são uma categoria profissional que se forjou na luta de moradores de rua pelo acesso ao trabalho com materiais recicláveis. Caso a mecanização e a automação não se insiram nessa perspectiva histórica de inclusão, podem reproduzir a exclusão; reprojetadas em uma perspectiva de uma adequação sociotécnica e antropotecnológica, essas tecnologias podem ser apropriadas pelos catadores para aumentar a eficiência e ampliar a inclusão. Duas alternativas, portanto, se colocam nesse momento histórico decisivo para resolver o problema dos resíduos urbanos: ou se aumenta a escala da reciclagem em uma 
perspectiva tecnocêntrica, apostando na mecanização da coleta e da triagem como estratégia principal, ou se amplia a atuação dos catadores na coleta e se aumenta a eficiência na triagem associando tecnologia e atividade humana em uma perspectiva antropocêntrica. Esses dois caminhos levam a concepções diferentes das tecnologias de mecanização e de automação e das formas como homens e máquinas interagem.

\section{Por um reprojeto dos sistemas sociotécnicos de triagem}

Sendo um problema originado do próprio sistema de produção, o lixo não tem solução trivial, o que impõe a necessidade de pesquisas que tenham como foco a proposição de melhorias para um sistema sustentável. É nesse intuito que este artigo analisou como funcionam as tecnologias transferidas da Europa para o Brasil e mostrou como a inobservância de elementos importantes no projeto das CMTs influenciou negativamente seu desempenho. A abordagem da antropotecnologia nos convida a investigar e perceber o que se encontra por detrás dos sistemas técnicos transferidos. Este artigo contribui para essa discussão emergente e necessária, uma vez que, para responder às recentes legislações mais restritivas quanto às práticas de enterramento, a tendência mais forte nos países periféricos é procurar soluções prontas desenvolvidas nos países centrais.

A pesquisa que deu origem a este artigo permitiu identificar os problemas e soluções encontrados no primeiro um ano e meio de funcionamento das CMTs paulistanas. As análises realizadas podem contribuir para o projeto de próximas centrais de triagem a serem construídas, inclusive nos países centrais, em diversos aspectos, intrínsecos e extrínsecos aos artefatos, dando mais coerência ao sistema sociotécnico de triagem.

Inicialmente, em relação aos próprios artefatos ou dispositivos técnicos, é possível repensar as interfaces entre homens e máquinas de modo a ter um sistema mais flexível. Um dos elementos-chave nesse sentido seria aumentar a margem de controle dos trabalhadores em relação à velocidade das esteiras transportadoras. Essa é a fórmula de sucesso adotada em ACs que utilizam esteiras e que nem por isso deixam de entregar produtos de alta qualidade ao mercado, além de manterem baixas as taxas de rejeito. Com uma maior possibilidade de regulação, os catadores conseguem adequar o funcionamento das esteiras à realidade da produção, que é sempre situada (como no caso dos SOs que param de funcionar, do fluxo denso nas esteiras etc.) ${ }^{14}$. 0 fluxo e o leiaute também devem ser pensados de modo a evitar algumas situações, como a de materiais de dimensões menores serem ocultados por outros de dimensões maiores. Os primeiros postos de trabalho devem então triar esses materiais maiores, e o leiaute deve ser pensado no sentido de facilitar isso. Recomenda-se ainda a adoção de triagem manual descentralizada, uma vez que permite que as intervenções humanas sejam feitas ao longo da linha, de forma mais distribuída, evitando gargalos. Parece interessante, por exemplo, a colocação de triagem manual de vidros e papelões mais volumosos no início do processo, solução eficiente já adotada de maneira quase que universal nas ACs. Por fim, não é razoável a utilização de triagem negativa em fluxos cujo material de interesse não seja predominante, como acontece no papel misto, que concentra toda triagem negativa - tanto em São Paulo quanto em São Francisco. Esse é um princípio que deve ser respeitado para evitar a ultra intensificação do ritmo de trabalho nessas esteiras e a deterioração na qualidade do material.

Em um nível intermediário, devem ser repensadas as formas de organização e gestão internas. Um aspecto desejável, que foi percebido na CMT-01, é a criação de uma dinâmica flexível de trabalho, em que o coordenador operacional assume um papel de facilitação e articulação entre os trabalhadores, estes dispondo de mais autonomia para sua própria regulação e regulação coletiva. Além disso, é importante

\footnotetext{
14 É sabido que na CMT-01 e em outras CMTs essa intervenção não seria trivial, uma vez que existe um balanceamento de massas que exige uma sincronicidade sutil entre as diferentes esteiras de uma linha. Mas inclusive isso é algo a ser repensado nesses sistemas, no sentido de aumentar o paralelismo de suas linhas.
} 
que se estabeleçam reuniões periódicas de Retorno de Experiência para que os fatos operacionais do cotidiano sejam debatidos e se criem melhores condições para cooperação horizontal e vertical.

Finalmente, considerando o tecido social, os problemas evidenciados podem ser resolvidos ou amenizados com o desenvolvimento de maior cooperação transversal no sistema. Isso pressupõe a criação de espaços e estratégias de desenvolvimento da competência não só dos operadores, mas também dos beneficiários, para que eles não disponibilizem na coleta materiais indesejáveis no processo, como é o caso dos materiais enroscantes e volumosos. Em outro nível, é desejável possibilitar maior integração entre a coleta e a triagem. Os coletores, ao compartilharem a forma de vida dos triadores, adquirem certas expertises e desenvolvem cooperações horizontais que os alimentam na realização de uma coleta mais coerente com o processo logo a jusante - no caso, a triagem (Campos et al., 2019). No caso dos países periféricos, os catadores sabem exatamente quais são os materiais problemáticos, pois sentem "na pele" as consequências desses materiais para o processo. Sabem, por exemplo, que o ideal é que o vidro seja coletado em um sistema exclusivo, mas, quando vem junto aos outros recicláveis, uma pré-triagem do vidro no ato da coleta já reduziria a incidência negativa desse material na planta. Dessa forma, a contratação das ACs para a coleta seletiva consegue aliar saberes importantes de dois pontos fortemente imbricados da cadeia da reciclagem: a coleta e a triagem. Um sistema integrado eficiente somente pode ser construído sobre uma rede de vínculos humanos e sociais organizados pelos próprios catadores.

\section{Referências}

Abrahão, J. (1985). Les processus de maîtrise technologique: implantation de distillerie de canne à sucre en milieu rural brésilien (Thèse de magistère). Conservatoire National des Arts et Métiers, Paris.

Akrich, M., Callon, M., Latour, B., \& Monaghan, A. (2002). The key to success in innovation Part I: the art of interessement. International Journal of Innovation Management, 6(2), 187-206.

http://dx.doi.org/10.1142/S1363919602000550.

Alexander, C. (1964). Notes on the synthesis of form. Cambridge: Harvard University Press.

Boudra, L. (2016). Durabilité du travail et prévention en adhérence. Le cas de la dimension territoriale des déchets dans l'activité de tri des emballages ménagers (Thèse de magistère). Université Lumière Lyon 2, Lyon.

Brooks, A. L., Wang, S., \& Jambeck, J. R. (2018). The Chinese import ban and its impact on global plastic waste trade. Science Advances, 4(6), eaat0131. http://dx.doi.org/10.1126/sciadv.aat0131. PMid:29938223.

Burton, R. R., Brown, J. S., \& Fischer, G. (1984). Skiing as a model of instruction. In Rogoff, B. J., \& Lave, J., eds Everyday cognition (pp. 140-149). Cambridge: Harvard University Press.

Campos, L. S. (2013). Processo de triagem dos materiais recicláveis e qualidade (Dissertação de mestrado). Universidade Federal de Minas Gerais, Belo Horizonte.

Campos, L. S., Gonçalves, J. T., Lima, F. D. P. A., Varella, C. V. S., \& Silva, A. R. (2019). The centrality of the waste pickers' work for the development of recycling in Brazil. In Proceedings of the 29th ISWA World Congress. Bizkaia, Spain: Sergofi.

Centro Mineiro de Referência de Resíduos - CMRR. (2012). Reciclar - catálogo de padronização dos materiais recicláveis. Belo Horizonte: CMRR.

Collins, H. (1990). Artificial experts. Cambrigde: MIT Press.

Collins, H. (2011). Mudando a ordem. Belo Horizonte: Fabrefactum.

Djemaci, B. (2009). Public waste management services in France: National analysis and case studies of Paris, Rouen, and Besançon (Working Paper, CIRIEC No. 2009/02). Belgian: CIRIEC.

Duarte, F., Conceiçao, C., Cordeiro, C., \& Lima, F. (2008). A integração das necessidades de usuários e projetistas como fonte de inovação para o projeto. Laboreal (Porto), 4(2), 59-71. http://dx.doi.org/10.4000/laboreal.11269. 
Durand, M., Cavé, J., \& Pierrat, A. (2019b). Quand le low-tech fait ses preuves: la gestion des déchets dans les pays du Sud. Urbanités, 12, 1-13.

Durand, M., Cavé, J., Delarue, J., Ke Bozec, A., \& Salenson, I. (2019a). Détourner les déchets. Innovations sociotechniques dans les villes du Sud (No. 54). Paris: AFD. Notes Techniques.

Ferreira, R. B., \& Lima, F. D. P. A. (2006). Metodologias ágeis: um novo paradigma de desenvolvimento de software. In Anais do II Workshop Um Olhar Sociotécnico Sobre a Engenharia de Software (Vol. 3, pp. 107-116). Rio de Janeiro: UFRJ.

Freyssenet, M. (1992). Processus et formes sociales d'automatisation. Sociologie du Travail, 34(4), 469-496. http://dx.doi.org/10.3406/sotra.1992.2611.

Geslin, P. (2017). Inside antorpotechnology: user and culture centered experience. Londres: ISTE. http://dx.doi.org/10.1002/9781119452775.

Guérin, F., Laville, A., Daniellou, F., Duraffourg, J., \& Kerguelen, A. (2001). Compreender o trabalho para transformálo: a prática da ergonomia. São Paulo: Blucher/Fundação Vanzolini.

Ip, K., Testa, M., Raymond, A., Graves, S. C., \& Gutowski, T. (2018). Performance evaluation of material separation in a material recovery facility using a network flow model. Resources, Conservation \& Recycling, 131, $192-205$. https://doi.org/10.1016/j.resconrec.2017.11.021.

Kessler, K. C. I. (2009). MRFing our way to diversion: capturing the commercial waste stream. materials recovery facility technology review. Recuperado em 22 de outubro de 2019, de http://www.dep.state.fl.us/waste/quick_topics/publications/shw/recycling/InnovativeGrants/IGYear9/finalrepo rt/Pinellas_IG8-06_Technology_Review.pdf

Lima, F. P. A. (2005). Norma e atividade humana. In Departamento Intersindical de Estatística e Estudos Socioeconômicos - DIEESE. Trabalho e abordagem pluridisciplinar: estudos Brasil, França e Argentina (pp. 51-68). São Paulo: DIEESE/CESIT.

Lima, F. P. A., Gonçalves, J. T., Campos, L. S., Souza, M. A., \& Valle, W. A. (2019). Estratégias de Desenvolvimento da Reciclagem com Participação dos Catadores. In Anais do IX Encontro Nacional da ANPPAS. Brasília: ANPPAS.

Lima, F. P. A., Varella, C. V. S., Oliveira, F. G., Parreiras, G., \& Rutkowski, J. (2011). Tecnologias sociais da reciclagem: efetivando políticas de coleta seletiva com catadores. Gerais: Revista Interstucional de Psicologia, 4(2), 131-146.

Mackenzie, D., \& Wajcman, J. (1999). The social shaping of technology. Buckingham: Open University Press.

Miranda, R., Monte, M. C., \& Blanco, A. (2013). Analysis of the quality of the recovered paper from commingled collection systems. Resources, Conservation and Recycling, 72, 60-66.

http://dx.doi.org/10.1016/j.resconrec.2012.12.007.

Oliveira, F. G. (2010). Processo de trabalho e produção de vínculos sociais: eficiência e solidariedade na triagem de materiais recicláveis (Dissertação de mestrado). Universidade Federal de Minas Gerais, Belo Horizonte.

Ong, C.-N. (1991). Ergonomics, technology transfer and developing countries. Ergonomics, 34(6), 799-814.

http://dx.doi.org/10.1080/00140139108967352.

Pietrobelli, C. (2018). Thechnology transfer for developing countries. In D. Schroeer \& M. Elena (Eds.), Technology transfer. Nova Iorque: Routledge.

Ribeiro, R., \& Collins, H. (2007). The bread-making machine: tacit knowledge and two types of action. Organization Studies, 28(9), 1417-1433. http://dx.doi.org/10.1177/0170840607082228.

Rutkowski, J.E., \& Rutkowski, E. (2015). Expanding worldwide urban solid waste recycling: the Brazilian social technology in waste pickers inclusion. Waste Management \& Research, 33(12), 1084-1093.

http://dx.doi.org/10.1177/0734242X15607424. PMid:26467319.

São Paulo. (2014). Plano de Gestão Integrada de Resíduos Sólidos da cidade de São Paulo. São Paulo: Diário Oficial do Município. 
São Paulo. Autoridade Municipal de Limpeza Urbana - AMLURB. (2020). Quantitativos: resíduos coletados no município. São Paulo: Prefeitura Municipal. Recuperado em 6 de julho de 2020, de https://www.prefeitura.sp.gov.br/cidade/secretarias/upload/subprefeituras/COLETA\%20SELETIVA\%20\%20Maio\%20de\%202020.pdf

Staub, C. (2017). China's slightly laxed limit does little for paper. Recuperado em 22 de outubro de 2019, de https://resource-recycling.com/recycling/2017/12/05/chinas-slightly-laxed-limit-little-paper/

Vandenberghe, F. (2010). Teoria social realista. Belo Horizonte: Editora UFMG.

Varella, C. V. S. (2011). Revirando o lixo: possibilidades e limites da reciclagem como alternativa de tratamento dos resíduos sólidos (Dissertação de mestrado). Universidade Federal de Minas Gerais, Belo Horizonte.

Vieira, M. C. M., Figueiredo Gallardo, A. L. C., De Oliveira e Aguiar, A., \& Gaudereto, G. L. (2019). São Paulo integrated management plan of solid waste in the perspective of the strategic environmental assessment. urbe. Revista Brasileira de Gestão Urbana, 11, e20180155. http://dx.doi.org/10.1590/2175-3369.011.e20180155.

Wisner, A. (1981). The effects of technology transfer on working conditions. In Proceedings of the Inter-Regional Tripartite Symposium on Occupational Safety, Health and Working Conditions Specifications in Relation to Transfer of Technology to the Developing Countries (pp. 179-192). Genebra, Suiça: UNESCO/UNEVOC.

Wisner, A. (1985). Quando voyagent les usines: essai d'anthropotechnologie. Paris: Syros.

Wisner, A. (1992). A antropotecnologia. Estudos Avançados, 6(16), 29-34. http://dx.doi.org/10.1590/S010340141992000300003.

Wisner, A. (1994). A inteligência no trabalho. São Paulo: Fundacentro.

\section{Editor: Fábio Duarte}

Recebido: Abr. 12, 2020

Aprovado: Ago. 16, 2020 